\title{
Behavioral evidence for left-hemisphere specialization of motor planning
}

\author{
Loes Janssen • Ruud G. J. Meulenbroek • \\ Bert Steenbergen
}

Received: 7 July 2010/ Accepted: 3 December 2010/Published online: 24 December 2010

(C) The Author(s) 2010. This article is published with open access at Springerlink.com

\begin{abstract}
Recent studies suggest that the left hemisphere is dominant for the planning of motor actions. This lefthemisphere specialization hypothesis was proposed in various lines of research, including patient studies, motor imagery studies, and studies involving neurophysiological techniques. However, most of these studies are primarily based on experiments involving right-hand-dominant participants. Here, we present the results of a behavioral study with left-hand-dominant participants, which follows up previous work in right-hand-dominant participants. In our experiment, participants grasped CD casings and replaced them in a different, pre-cued orientation. Task performance was measured by the end-state comfort effect, i.e., the anticipated degree of physical comfort associated with the posture that is planned to be adopted at movement completion. Both left- and right-handed participants showed stronger end-state comfort effects for their right hand compared to their left hand. These results lend behavioral support to the left-hemisphere-dominance motion-planning hypothesis.
\end{abstract}

Keywords Handedness · Hemisphere dominance · Motor planning $\cdot$ Bimanual

\footnotetext{
L. Janssen $(\bowtie) \cdot$ R. G. J. Meulenbroek · B. Steenbergen

Donders Institute for Brain, Cognition and Behaviour, Centre for Cognition, Radboud University Nijmegen, P.O. Box 9104, 6500 HE Nijmegen, The Netherlands e-mail: 1.janssen@donders.ru.nl

L. Janssen · B. Steenbergen

Behavioural Science Institute, Radboud University Nijmegen, Nijmegen, The Netherlands
}

\section{Introduction}

On average, 9 out of 10 individuals in the normal population is right-hand-dominant, which means that these individuals have a preference to perform unimanual actions, like reaching for a target or manipulate objects, with their right hand (a.o. Annett 2004; Goble and Brown 2008). This preference to use one hand over the other has been shown to be accompanied by an advantage in motor performance, including increases in the strength, speed and consistency of movements (see Goble and Brown 2008 for a review on upper limb asymmetries in sensorimotor performance). Although it was previously thought that the non-dominant hand was inferior for most aspects of motor control, more recent theories state that each hand is specialized for certain aspects of compound movements. For example, the dominant hand is superior for the precise control of movement trajectories, whereas the nondominant hand has a specialized role for positional control (Haaland et al. 2004; Sainburg and Schaefer 2004; Serrien et al. 2006; Wang and Sainburg 2007). A question of interest is whether this difference between the dominant and non-dominant hand in motor execution also holds for motor planning. Motor planning can be defined as the formulation of a strategy of action taking into account the future demands associated with the goal of the action (Gentilucci et al. 1997; Johnson-Frey et al. 2004), whereas motor execution is the implementation of this strategy. Our main research question is whether motor planning of dominant hand actions is different from motor planning of non-dominant hand actions and whether this dominance is similar for both left- and right-hand-dominant participants.

Recently, we conducted a behavioral experiment on motor planning in right-handed individuals via the examination of the end-state comfort effect (Janssen et al. 2009). 
This is the phenomenon that people generally strive to end their movements or object manipulations in a comfortable posture, even when this necessitates them to grasp the object at first with an awkward posture (Rosenbaum et al. 1992, 1996; Weigelt et al. 2006). By analyzing how participants grasped an object, we deduced whether the movement was planned in advance. We showed that the end-state comfort effect was more often present for the participants' right hand than for their left hand, suggesting that motor planning is a specialized function of the left hemisphere (Janssen et al. 2009).

The hypothesis that the left hemisphere plays a dominant role not only in the execution (in right-handers) but also in the planning of skilled movements has been repeatedly confirmed (e.g., Frey 2008; Haaland et al. 2000; Kim et al. 1993; Leiguarda and Marsden 2000). First, limb apraxia, an impairment in the representation of limb movements or their selection or retrieval, is strongly associated with left-hemisphere damage (Haaland et al. 2000; Leiguarda and Marsden 2000; Lunardelli et al. 2008; Liepmann 1920; Rothi and Heilman 1997). Second, converging evidence in participants with (congenital) lefthemisphere damage shows that these participants have difficulties to anticipate their grip to the upcoming goal in an object manipulation task, which is a clear indication that they have impaired motor planning (Crajé et al. 2009; Mutsaarts et al. 2007; see also Hermsdorfer et al. 1999). A third line of evidence originates from motor imagery research. Motor imagery may be regarded as a prerequisite for motor planning: Individuals who are unable to imagine movements of their own body (parts) have been shown to have difficulties with anticipating the consequences of their actions (Johnson et al. 2001; Mutsaarts et al. 2007; Steenbergen et al. 2007). Left-brain-damaged patients showed impairments to use motor imagery in contrast to right-brain-damaged patients, who did not show these impairments or to a much lesser extent (Daprati et al. 2010; Mutsaarts et al. 2007; Sabate et al. 2004). In addition, studies in healthy participants involving various neurophysiological techniques showed increased activity in left premotor, supplementary motor and parietal cortices, or enhanced excitability of the left primary motor cortex during motor imagery (Bonda et al. 1995; Fadiga et al. 1999; Kuhtz-Buschbeck et al. 2003; Stinear et al. 2006, 2007; Yahagi and Kasai 1999). Fourth, the preparation of overt movements was more interfered by transcranial magnetic stimulation (TMS) over the left premotor area compared to TMS over the right premotor area (Schluter et al. 1998), and brain activation patterns were more pronounced in the left sensorimotor area compared to the right one during movement preparation (Urbano et al. 1998).

The studies discussed above clearly point to lefthemisphere dominance for motor planning of skilled actions. However, an important limitation of the evidence thus far is that the participants of the experiments were all right-hand-dominant. It may therefore well be hypothesized that the results found were due to experience, or simply hand dominance, and less to a left-hemisphere specialization. To test this hypothesis, it is interesting to examine whether this left-hemisphere dominance for motor planning is also present in left-handed individuals when using their dominant left hand. If such a result is found, it would make a strong case for a generic left-hemisphere motion-planning specialization, irrespective of hand dominance. Only a few studies have focused on this topic.

Frey et al. (2005) tested tool-use skills in two split-brain patients, of which one was right-hand-dominant and the other left-hand-dominant. Both patients performed all task conditions best with their right hand. When visual stimuli were presented to either their left or right visual field (corresponding to the right or left hemisphere, respectively), both patients performed better with their right hand when the stimulus was presented to the left hemisphere versus their left hand when the stimulus was presented to the right hemisphere. Thus, even though the left-handed patient acted normally upon the tools with her left hand (that is controlled by the right hemisphere), her performance in this task was best with her right hand (controlled by the left hemisphere). From this study, it may be concluded that the representation of skilled actions is a lefthemisphere function that is independent of handedness. Although the results are straightforward, they are based on the data of only one left-hand-dominant participant. Adding to these findings are the results of an fMRI experiment in strongly left-handed participants (Frey 2008). This study revealed that pantomiming tool use resulted in largely the same brain activations as in right-handed participants, i.e., an increase in activity within the same left-lateralized regions. The results from a TMS experiment in which participants had to imagine tapping movements with their fingers, however, were less straightforward (Yahagi and Kasai 1999). Although right-handed participants showed MEP facilitation that was larger when they imagined moving their right hand compared to their left hand, left-handed participants showed MEP facilitations that were similar when imagining either left- or right-hand movements. The latter finding suggests that the processes involved in motor imagery and therefore likely also in motor planning may be less lateralized in left-handers but not necessarily dominant in either hemisphere. This idea is supported by a recent study on grasping behavior of lefthanders in a natural setting (Gonzalez et al. 2007). The researchers have observed that left-handed participants use their non-dominant hand in half of the precision grasps, whereas the right-handed participants use their non-dominant hand in less than a quarter of all precision grasps, indicating that the selection of which hand to use is less lateralized in lefthanders. 
To sum up, overall, there are only a few studies that focused on motor planning in left-hand-dominant participants. These studies suggest that the organization of motor control in these participants is not a mirror image of that in right-handers. Still, it is debatable whether the left hemisphere is dominant in the motor planning of left-handers, as previous studies report no asymmetry in either the facilitation of motor-evoked potentials in the actual usage of both hands in left-handers. In the following, we will present a study in which motor planning was examined in left-handed participants to test the left-hemisphere dominance hypothesis. To that aim, we replicated a study that was performed previously in right-handed participants (Janssen et al. 2009), but now in left-handers.

\section{Experiment}

The goal of this experiment was to test the left-hemisphere dominance hypothesis for motor planning in left-handdominant participants. We tested this by having these participants performing a CD-placement task. The task performance was measured using the end-state comfort effect, which reflects a major component of motor planning, i.e., whether the grip posture used is adapted to the final goal (Rosenbaum et al. 1992, 1996; Weigelt et al. 2006). If the left hemisphere is indeed specialized for motor planning of either hand, we expect a right-hand advantage for end-state comfort. Conversely, a dominant (left) hand advantage for end-state comfort would reject the left-hemisphere dominance hypothesis and rather suggests a hand dominance effect on end-state comfort.

\section{Methods}

\section{Participants}

Ten left-hand-dominant participants (mean age $=21.1$ years/months, $\mathrm{SD}=1.10$ years $/$ months, 1 male) were included in the present study. Handedness was confirmed by a score of $\leq-55$ on the ten-item version of the Edinburgh Handedness Inventory (Oldfield 1971), with a mean score of $-79(\mathrm{SD}=11)$. Participants received either course credits or 10 Euros for their participation, and they were naïve with regard to the purpose of the study. The experiments were conducted to conform the standards of the declaration of Helsinki and in accordance with local ethical guidelines.

\section{Experimental setup}

The experimental setup consisted of a large CD rack consisting of four boxes $(15 \times 15 \mathrm{~cm})$ in which the $C D$ casings (CDs in what follows) could be placed either horizontally or vertically (Fig. 1). The two upper boxes had green LEDs on the upper and right sides, which indicated the required end orientation of the CDs. In addition, and as a further cue, the borders of the upper boxes were covered with strips of green (on the upper and right sides) and black (on the lower and left sides) paper. The CDs also had a green and a black side, which enabled us to request for a CD rotation of either $0^{\circ}$ or $180^{\circ}$ (and $90^{\circ}$ or $-90^{\circ}$ ), by the instruction that the $\mathrm{CD}$ had to be placed with the green side facing the green LED.

\section{Task}

Participants were seated right in front of a table with the $\mathrm{CD}$ rack on it. Each trial started with the participant's hands on the table. The participant always had to pick up two CDs simultaneously from the lower boxes and place them in the upper boxes, with their green sides facing the green LEDs. Thus, when the LED on the upper side lighted, the CD had to be placed horizontally with the green side up, and when the LED on the right site lighted, the CD had to be placed vertically with the green side to the right. Participants were free to select the grips with which they grasped the CDs.

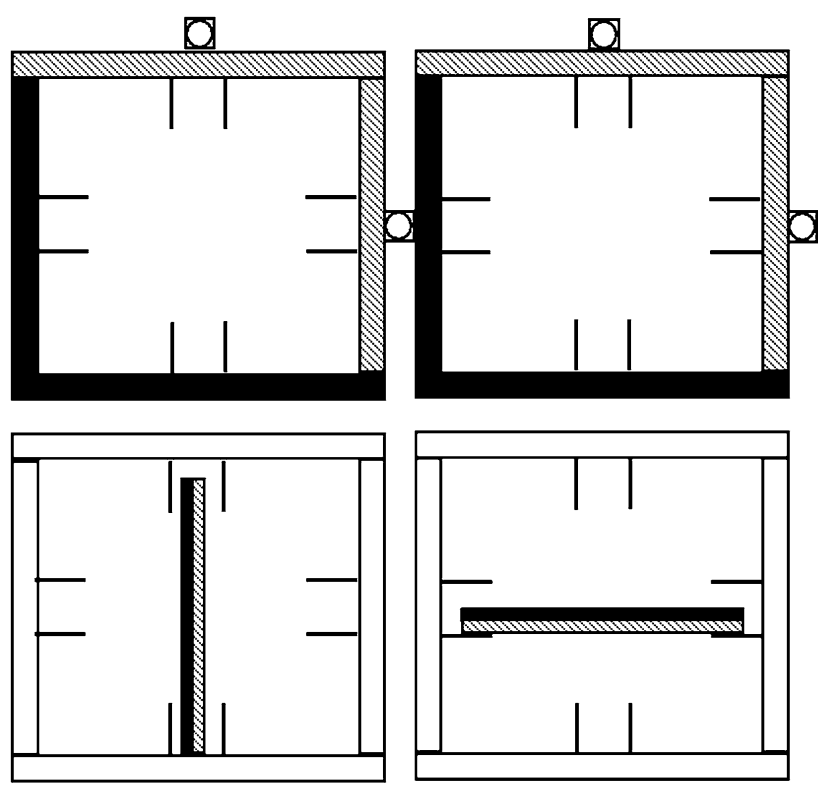

Fig. 1 Schematic drawing of the experimental setup. CDs have one green side (hatched) and one black side and are located in the lower boxes. The small circles on the top and right side of the upper boxes represent the LEDs. The upper boxes are covered with strips of green (hatched) and black paper. This figure is adapted from Janssen et al. (2009) 


\section{Experimental design}

The experiment consisted of 24 conditions in which we systematically manipulated the end orientation (horizontal or vertical) and the required rotation $\left(-90^{\circ}, 0^{\circ}, 90^{\circ}\right.$ or $\left.180^{\circ}\right)$ of the CD for each hand (left or right). This resulted also in both horizontal and vertical start orientations. Theoretically, participants could also make a rotation of $270^{\circ}$ in the opposite direction when a rotation of $90^{\circ}$ was required, but our previous study showed that this hardly occurred $(<2 \%$ of trials). Conditions were such that one CD always had to be rotated $180^{\circ}$ to place it horizontally or vertically. The required rotation for the other $\mathrm{CD}$ was $0^{\circ}, 90^{\circ}$ pronation or $90^{\circ}$ supination. These manipulations resulted in 2 possibilities for the $180^{\circ}$ rotating arm ( 2 orientations: horizontal or vertical) and 6 possibilities for the other arm (3 rotations $\times 2$ orientations). As the rotations could be performed with either hand, this resulted in a total of $2 \times 2 \times 6=24$ conditions. Participants performed 120 trials that were administered in five blocks of the 24 conditions in a randomized order. Trials within a block were repeated at the end of that block in case the participant ended the movement in the wrong orientation. Before the start of the experimental trials, participants performed 12 practice trials to check whether the task was understood correctly and to familiarize themselves with the task.

\section{Comfort ratings}

To determine comfort of the postures, we asked participants to give a rating reflecting comfort to all biomechanically possible postures that could be used to end the CD placement (see Janssen et al. 2009 for a detailed description of the methods). The participant was asked to adopt each of the five end postures for each hand (i.e., horizontal overhand, horizontal underhand, vertical with thumb up, vertical pronated with thumb down and vertical supinated with thumb down, see Table 1) and to give a rating between 1 and 5 reflecting comfort of the posture, with 1 being very uncomfortable and 5 being very comfortable. Comfort was assessed twice, once before and once after the experiment.

\section{Data analysis}

The comfort ratings were analyzed using a repeatedmeasures ANOVA including two within-subject factors: Hand (2 levels: left or right) and Posture (5 levels: horizontal overhand, horizontal underhand, vertical with thumb up, vertical pronated with thumb down and vertical supinated with thumb down). Post hoc pairwise comparisons were conducted for the different levels of Posture.

For each experimental trial, we registered the rotation of the hand (pronation or supination) and the side of the
Table 1 Mean comfort ratings (and standard deviation) for the end postures

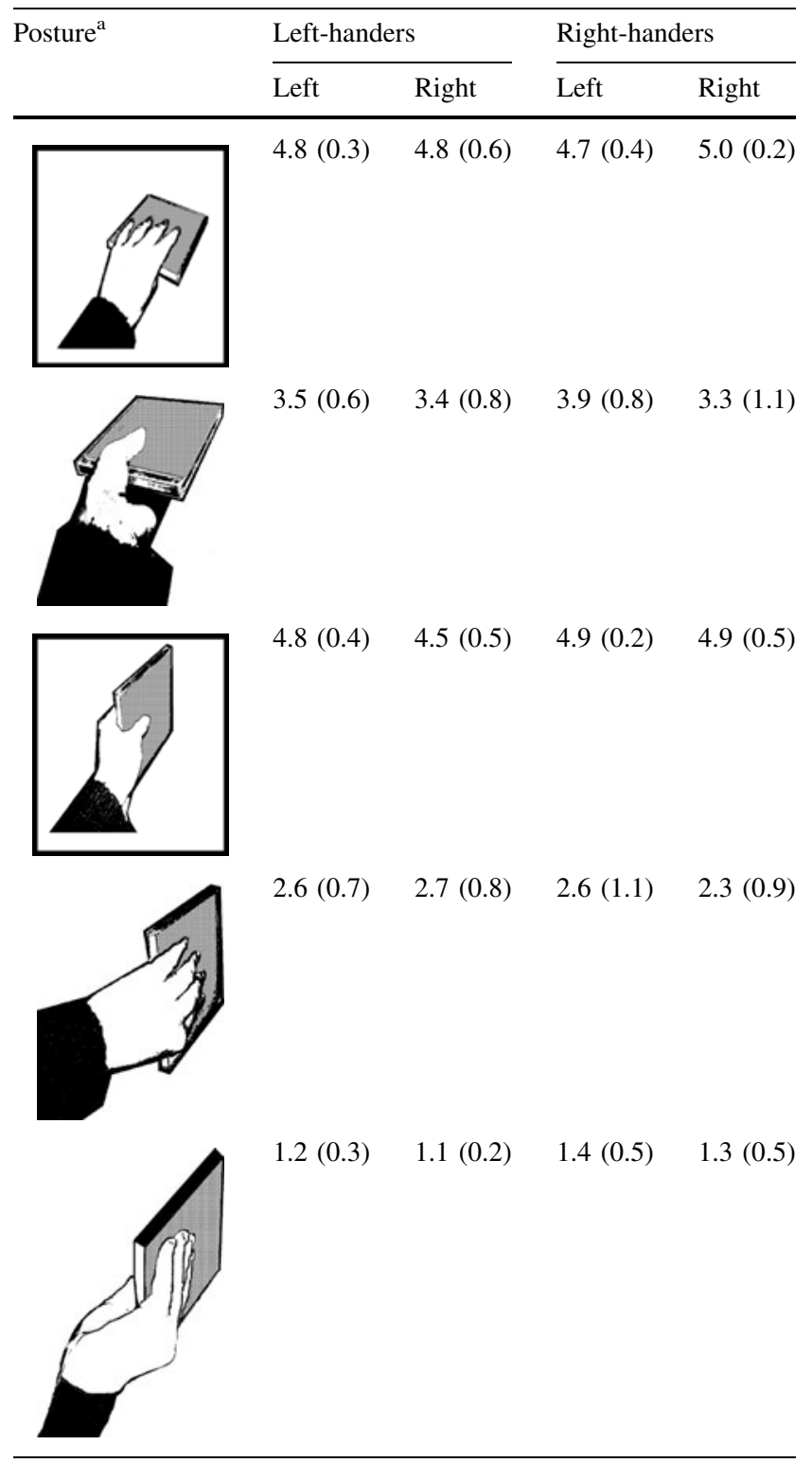

Numbers for right-handers are adapted from Janssen et al. (2009)

a Postures are depicted for the left hand and display the following postures, respectively: horizontal overhand, horizontal underhand, vertical with thumb up, vertical pronated with thumb down and vertical supinated with thumb down. Postures with bold borders were defined as comfortable

thumb on the $\mathrm{CD}$ (on the green or on the black side) while grasping the $\mathrm{CD}$. For this purpose, experimental trials were videotaped. Based on these registrations and on the results of the comfort scores, we categorized the adopted end postures to be either horizontal or vertical and either comfortable or uncomfortable, and the rotation to be $0^{\circ}$, $90^{\circ}$ or $180^{\circ}$. We investigated which factors had influenced the proportion of comfortable end postures by performing a repeated-measures ANOVA including three within-subject 
factors: Hand ( 2 levels: left or right), Rotation ( 3 levels: $0^{\circ}$, $90^{\circ}$ or $\left.180^{\circ}\right)$ and Orientation ( 2 levels: a horizontal or vertical cued end orientation of the $\mathrm{CD}$ ).

\section{Results}

The comfort ratings for the different end postures for each hand are shown in Table 1. The ANOVA on the comfort scores revealed no significant effect for the factor Hand $(F(1,9)=1.12, P=0.32)$ and a large effect for Posture $(F(1,9)=132.94, P<0.001)$. Post hoc pairwise comparisons showed that for the horizontal postures, the overhand grip was rated more comfortable than the underhand grip $(t(9)=7.01, P<0.001)$. For the vertical start orientations, a grip type with the thumb pointing up was rated more comfortable than both a pronated grip with the thumb pointing down $(t(9)=8.31, P<0.001)$ and a supinated grip with the thumb pointing down $(t(9)=17.29, P<0.001)$. Therefore, similar to our previous study (Janssen et al. 2009), we defined a horizontal overhand posture and a vertical posture with the thumb up as comfortable, whereas a horizontal underhand posture and a vertical posture with the thumb down were defined as uncomfortable.

For the experimental trials, the proportion of comfortable end postures is displayed in Fig. 2, for the hand used and the orientation of the CD separately. The ANOVA revealed significant main effects for Hand $(F(1,9)=11.46$, $P<0.01)$, Orientation $(F(1,9)=73.46, P<0.001)$ and Rotation $(F(2,18)=18.21, P<0.001)$, as well as an interaction effect for Hand $*$ Orientation $(F(1,9)=13.89$, $P<0.01)$. Overall, the proportion of comfortable end postures was larger for the right compared to left hand, for the vertical compared to horizontal orientation and for small compared to large rotation angles. All other possible twoand three-way interactions were non-significant. First, in line with the left-hemisphere dominance hypothesis, we found that the left-handed participants ended more often comfortable with their right (non-dominant) hand, compared to their left (dominant) hand. This indicates that advance motor planning does not simply correlate with hand dominance or experience. Second, the end-state comfort effect was stronger when ending vertical compared to horizontal. The horizontal underhand posture, which we a priori denoted as uncomfortable, may not have been that uncomfortable compared to the vertical uncomfortable postures with the thumb down. This was indeed confirmed by a higher comfort rating for the horizontal 'uncomfortable' posture (mean rating of 3.45), compared to the vertical uncomfortable postures (mean ratings of 2.65 and 1.10). This might be explained in terms of larger differences in the precise control between the two vertical conditions versus the two horizontal conditions. These higher precision requirements in the vertical conditions might have caused the larger end-state comfort effect, which is previously described as the precision hypothesis (Short and Cauraugh 1999). Third, the proportion of comfortable endings decreased with an increase in rotation angle. This was expected as conditions involving small rotation angles did not require anticipatory motor planning (a comfortable posture at the start is also a comfortable posture at the end when the rotation angle is $0^{\circ}$ ).

The interaction effect for Hand * Orientation suggests that the difference between the left and right hand was not evenly distributed among the horizontal and vertical endings. Post hoc analyses revealed that the proportion of comfortable endings was significantly different between the left and right hand only for the horizontal end postures $(t(9)=3.47, P<0.01)$ and not for the vertical end postures $(t(9)=0.63, P=0.55)$.

Thus, first and foremost, the main effect of Hand clearly shows that the right hand performs better on anticipatory motor planning than the left hand and that this effect is primarily due to the horizontal end postures and not the vertical end postures.
Fig. 2 Mean end-state comfort for both handedness groups. The bars and the numbers in them depict the percentages of trials in which participants ended their movements comfortably, separated for the left and right hands and for horizontal endings (filled bars) and vertical endings (hatched bars). The error bars display two standard errors. The data for righthanders (right graph) are adapted from Janssen et al. (2009)
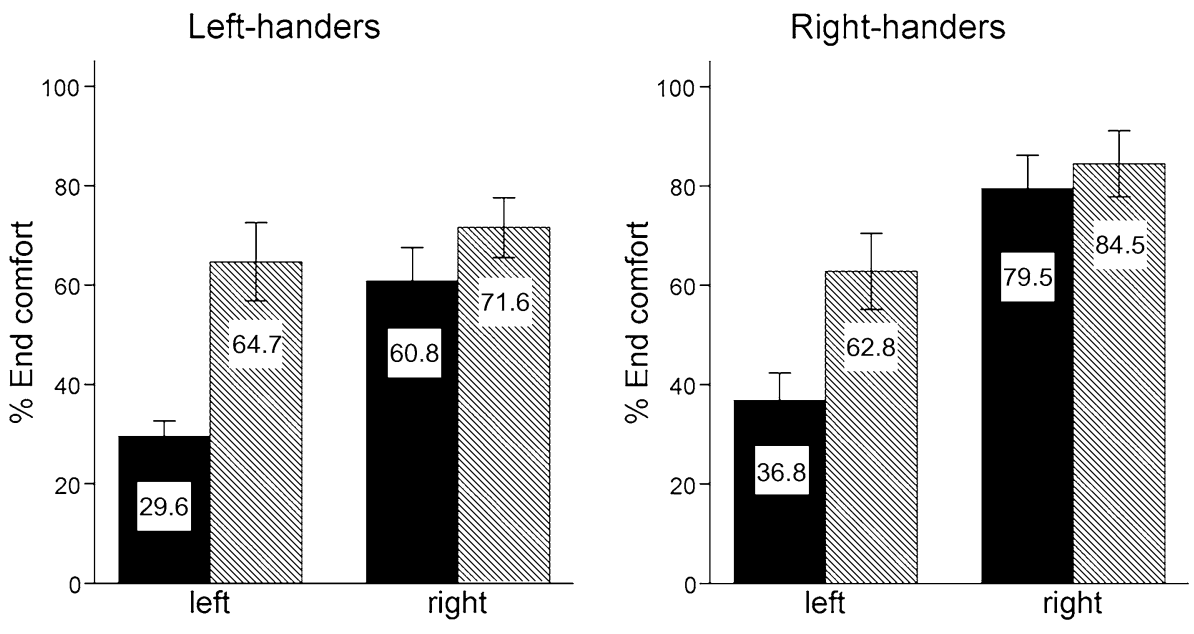
Comparison with right-handers

The results from the present study can be compared to the results from our previous study (Janssen et al. 2009), as the experimental setup and procedure were the same. In that experiment, we measured ten right-handed participants (mean age $=20.6$ years $/$ months, $\mathrm{SD}=1.9$ years $/$ months, 2 males), all had scores of $\geq 60$ on the Edinburgh Handedness Inventory with a mean score of $80(\mathrm{SD}=14)$. We repeated the analysis, including the data from the right-handers and adding the between-subjects factor Handedness (2 levels: left-handed or right-handed). Again, significant main effects were found for $\operatorname{Hand}(F(1,18)=33.78, P<0.001)$, Orientation $(F(1,18)=32.93, P<0.001)$ and Rotation $(F(2,36)=25.00, P<0.001)$, as well as an interaction effect for Hand $*$ Orientation $(F(1,18)=12.68, P<0.01)$. In addition, all other possible two-, three- and four-way interactions were non-significant. Most importantly, we did not find a significant effect for Handedness $(F(1,18)=3.135, P=0.09)$ or an interaction effect for Hand $*$ Handedness $(F(1,18)=1.59, P=0.22)$, indicating that the results were similar for both handedness groups (Fig. 2). To further investigate the (lack of a) relation between handedness and the end-state comfort effect, we performed a correlation analysis between the degree of handedness as defined by the Edinburgh Handedness Inventory and the proportion of comfortable end postures (see also Dassonville et al. 1997). The correlation was not significant for the proportion of comfortable end postures of either the left hand $(r=0.20, P=0.41)$, the right hand ( $r=0.38, P=0.11$ ), or the difference between the left and right hand ( $r=0.24, P=0.32$ ). This further emphasizes the similarity between both handedness groups, which strengthens the left-hemisphere dominance hypothesis for motor planning over the hand dominance hypothesis.

One final note should be made that further supports the left-hemisphere specialization for motor planning over the alternative dominant hand experience hypothesis. It is well known that right-handers are generally less experienced with their non-dominant hand compared to left-handers with their non-dominant hand (Gonzalez et al. 2007). However, we found equal performance in the left hands of both handedness groups. This finding goes against the alternative explanation that motor planning is associated with dominant hand experience.

\section{Discussion}

In this paper, we outlined the left-hemisphere dominance hypothesis for motor planning and its support from various lines of research mainly involving right-handed participants. A few studies also focused on left-handed individuals, and although some studies do point to clear left-hemisphere dominance for motor planning in lefthanders as well, the evidence is less conclusive than in right-handers. Therefore, we performed an experiment to add behavioral evidence by testing the performance of lefthanded individuals on a motor planning task. These participants showed a stronger end-state comfort effect for their right hand (predominantly controlled by the left hemisphere) compared to their left hand, implying lefthemisphere dominance for motor planning also in lefthanders.

An alternative explanation for this finding is that motor planning in left-handers relies more on ipsilateral control from their right motor-dominant hemisphere to plan movements of their right hand. For right-handed participants, it has been shown that the ipsilateral (right) hemisphere can play a role in the planning of right-hand reaching movements (Busan et al. 2009). However, the majority of literature report strong representations of righthand movements in the contralateral (left) hemisphere (e.g., Kuhtz-Buschbeck et al. 2003; Kim et al. 1993; Johnson-Frey et al. 2005). Furthermore, Frey (2008) has reported that left-handers show the same brain activation pattern, i.e., a distributed network of areas in the left hemisphere, as right-handers when planning and performing tool-use pantomimes. This renders it unlikely that the right hemisphere in left-handers is dominant for the planning of right-hand movements.

Another alternative explanation for the finding that lefthanders perform better on our motor planning task with their right hand compared to their left hand is that we live in a 'right-handed world' (Gonzalez et al. 2007). As most people are right-handed, many tools and arrangements are adjusted to right-handers, like scissors, a computer mouse on the right side of a keyboard, etc. It could be that our lefthanded participants are so well adapted to these situations that they have become experienced with their right hand. However, from the handedness inventory, we can conclude that they mostly use their left hand for a variety of (daily) tasks. In fact, all left-handed participants answered that they always, or most often, used their left hand when opening a lid from a box, which is in our view the item that most resembled picking up a CD.

A third alternative explanation for the right-hand advantage in our experiment postulates that the left hemisphere is not necessarily dominant for the planning but rather for the execution of precision grasps and that this is taken into account when planning these movements. The study on precision grasping by Gonzalez et al. (2006) might support this by showing that left-handers more often use their non-dominant hand than do right-handers in a precision grasping task. However, the left-handed participants in our study were classified as being left-handed 
because they indicated that they use their left hand for the various tasks of the handedness inventory, which consists mainly of tasks with high precision requirements. If they prefer to use their left hand in most of these precision demanding tasks, then a left-hemisphere advantage in the execution of precision grasps seems unlikely.

The left-hand dominance for motor execution in lefthanders may be the cause that some behavioral studies report equal results for both hands in left-handers and asymmetric results for both hands in right-handers when motor tasks are considered (e.g., Gonzalez et al. 2007). In those experiments, the planning of movements as controlled by the left hemisphere and the execution as controlled by the right hemisphere may contribute to an equal performance for both hands. In right-handed participants, however, the left hemisphere is dominant for both the planning and execution of movements, which leads to a better performance for the right hand compared to the left hand. In our experiment, we measured the performance on motor planning, not execution. Nevertheless, if the dominance on motor execution in the right hemisphere had interfered with our measurements by improving the performance of the left hand, the effect that we found would be even an underestimation.

In the present study, we showed asymmetries in task performance at a behavioral level. Specifically, we showed an advantage in end-state comfort effect for the right hand also in left-handers, which strengthens the left-hemisphere dominance hypothesis for motor planning. In addition, we showed a larger end-state comfort effect for the vertical condition than for the horizontal condition. Although at present we do not have a conclusive explanation for this finding, it is possible that the precision requirement was larger when end-state comfort was not met for the vertical condition than when end-state comfort was not met for the horizontal condition.

Open Access This article is distributed under the terms of the Creative Commons Attribution Noncommercial License which permits any noncommercial use, distribution, and reproduction in any medium, provided the original author(s) and source are credited.

\section{References}

Annett M (2004) Hand preference observed in large healthy samples: classification, norms and interpretations of increased non-righthandedness by the right shift theory. Br J Psychol 95:339-353

Bonda E, Petrides M, Frey S, Evans A (1995) Neural correlates of mental transformations of the body-in-space. Proc Natl Acad Sci U S A 92(24):11180-11184

Busan P, Jarmolowska J, Semenic M, Monti F, Pelamatti G, Pizzolato G, Battaglini PP (2009) Involvement of ipsilateral parietooccipital cortex in the planning of reaching movements: evidence by tms. Neurosci Lett 460(2):112-116
Crajé C, van der Kamp J, Steenbergen B (2009) Visual information for action planning in left and right congenital hemiparesis. Brain Res 1261:54-64

Daprati E, Nico D, Duval S, Lacquaniti F (2010) Different motor imagery modes following brain damage. Cortex 46(8):1016-1030. doi:10.1016/j.cortex.2009.08.002

Dassonville P, Zhu XH, Ugurbil K, Kim SG, Ashe J (1997) Functional activation in motor cortex reflects the direction and the degree of handedness. Proc Natl Acad Sci U S A 94:14015-14018

Fadiga L, Buccino G, Craighero L, Fogassi L, Gallese V, Pavesi G (1999) Corticospinal excitability is specifically modulated by motor imagery: a magnetic stimulation study. Neuropsychologia 37(2):147-158

Frey SH (2008) Tool use, communicative gesture and cerebral asymmetries in the modern human brain. Philos Trans R Soc Lond B Biol Sci 363(1499):1951-1957

Frey SH, Funnell MG, Gerry VE, Gazzaniga MS (2005) A dissociation between the representation of tool-use skills and hand dominance: insights from left- and right-handed callosotomy patients. J Cogn Neurosci 17(2):262-272

Gentilucci M, Negrotti A, Gangitano M (1997) Planning an action. Exp Brain Res 115(1):116-128

Goble DJ, Brown SH (2008) The biological and behavioral basis of upper limb asymmetries in sensorimotor performance. Neurosci Biobehav Rev 32(3):598-610

Gonzalez CLR, Ganel T, Goodale MA (2006) Hemispheric specialization for the visual control of action is independent of handedness. J Neurophysiol 95(6):3496-3501

Gonzalez CLR, Whitwell RL, Morrissey B, Ganel T, Goodale MA (2007) Left handedness does not extend to visually guided precision grasping. Exp Brain Res 182(2):275-279

Haaland KY, Harrington DL, Knight RT (2000) Neural representations of skilled movement. Brain 123:2306-2313

Haaland KY, Prestopnik JL, Knight RT, Lee RR (2004) Hemispheric asymmetries for kinematic and positional aspects of reaching. Brain 127:1145-1158

Hermsdorfer J, Laimgruber K, Kerkhoff G, Mai N, Goldenberg G (1999) Effects of unilateral brain damage on grip selection, coordination, and kinematics of ipsilesional prehension. Exp Brain Res 128(1-2):41-51

Janssen L, Beuting M, Meulenbroek RGJ, Steenbergen B (2009) Combined effects of planning and execution constraints on bimanual task performance. Exp Brain Res 192:61-73

Johnson SH, Corballis PM, Gazzaniga MS (2001) Within grasp but out of reach: evidence for a double dissociation between imagined hand and arm movements in the left cerebral hemisphere. Neuropsychologia 39(1):36-50

Johnson-Frey SH, McCarty ME, Keen R (2004) Reaching beyond spatial perception: effects of intended future actions on visually guided prehension. Vis Cogn 11(2-3):371-399

Johnson-Frey SH, Newman-Norlund R, Grafton ST (2005) A distributed left hemisphere network active during planning of everyday tool use skills. Cereb Cortex 15(6):681-695

Kim SG, Ashe J, Hendrich K, Ellermann JM, Merkle H, Ugurbil K, Georgopoulos AP (1993) Functional magnetic-resonance-imaging of motor cortex-hemispheric-asymmetry and handedness. Science 261(5121):615-617

Kuhtz-Buschbeck JP, Mahnkopf C, Holzknecht C, Siebner H, Ulmer S, Jansen O (2003) Effector-independent representations of simple and complex imagined finger movements: a combined fmri and tms study. Eur J Neurosci 18(12):3375-3387

Leiguarda RC, Marsden CD (2000) Limb apraxias-higher-order disorders of sensorimotor integration. Brain 123:860-879

Liepmann H (1920) Apraxie. Ergeb ges Med 1:516-543 
Lunardelli A, Zadini A, Gigli G, Ida Rumiati R (2008) Praxic and executive components in tool use learning: the role of imitation. Cogn Neuropsychol 25(7-8):1077-1098

Mutsaarts M, Steenbergen B, Bekkering H (2007) Impaired motor imagery in right hemiparetic cerebral palsy. Neuropsychologia 45(4):853-859

Oldfield RC (1971) Assessment and analysis of handedness-edinburgh inventory. Neuropsychologia 9(1):97-113

Rosenbaum DA, Barnes HJ, Vaughan J, Jorgensen MJ (1992) Time course of movement planning-selection of handgrips for object manipulation. J Exp Psychol Learn Mem Cogn 18(5):1058-1073

Rosenbaum DA, van Heugten CM, Caldwell GE (1996) From cognition to biomechanics and back: the end-state comfort effect and the middle-is-faster effect. Acta Psychol 94(1):59-85

Rothi LGJ, Heilman KM (1997) Apraxia: the neuropsychology of action. Psychology Press, Hove

Sabate M, Gonzalez B, Rodriguez M (2004) Brain lateralization of motor imagery: motor planning asymmetry as a cause of movement lateralization. Neuropsychologia 42(8):1041-1049

Sainburg RL, Schaefer SY (2004) Interlimb differences in control of movement extent. J Neurophysiol 92(3):1374-1383

Schluter ND, Rushworth MFS, Passingham RE, Mills KR (1998) Temporary interference in human lateral premotor cortex suggests dominance for the selection of movements-a study using transcranial magnetic stimulation. Brain 121:785-799

Serrien DJ, Ivry RB, Swinnen SP (2006) Dynamics of hemispheric specialization and integration in the context of motor control. Nat Rev Neurosci 7(2):160-167
Short MW, Cauraugh JH (1999) Precision hypothesis and the endstate comfort effect. Acta Psychol 100(3):243-252

Steenbergen B, van Nimwegen M, Crajé C (2007) Solving a mental rotation task in congenital hemiparesis: motor imagery versus visual imagery. Neuropsychologia 45(14):3324-3328

Stinear CM, Fleming MK, Byblow WD (2006) Lateralization of unimanual and bimanual motor imagery. Brain Res 1095: $139-147$

Stinear CM, Fleming MK, Barber PA, Byblow WD (2007) Lateralization of motor imagery following stroke. Clin Neurophysiol 118(8):1794-1801

Urbano A, Babiloni C, Onorati P, Carducci F, Ambrosini A, Fattorini L, Babiloni F (1998) Responses of human primary sensorimotor and supplementary motor areas to internally triggered unilateral and simultaneous bilateral one-digit movements. A high-resolution eeg study. Eur J Neurosci 10(2):765-770

Wang JS, Sainburg RL (2007) The dominant and nondominant arms are specialized for stabilizing different features of task performance. Exp Brain Res 178(4):565-570

Weigelt M, Kunde W, Prinz W (2006) End-state comfort in bimanual object manipulation. Exp Psychol 53(2):143-148

Yahagi S, Kasai T (1999) Motor evoked potentials induced by motor imagery reveal a functional asymmetry of cortical motor control in left- and right-handed human subjects. Neurosci Lett 276(3):185-188 